Deciphering Discord: How Drosophila research has enhanced our understanding of the importance of FMRP in different spatial and temporal contexts

Eliana D. Weisz ${ }^{1 *}$, Rachel E. Monyak ${ }^{1 *}$ and Thomas A. Jongens ${ }^{1 \#}$

1) Department of Genetics, University of Pennsylvania Perelman School of Medicine Philadelphia, PA 19104, *both authors have contributed equally to this work

\# Corresponding author: email: tjongens@gmail.com 


\begin{abstract}
:
Fragile X Syndrome (FXS) is the most common heritable form of intellectual impairment as well as the leading monogenetic cause of autism. In addition to its canonical definition as a neurodevelopmental disease, recent findings in the clinic suggest that FXS is a systemic disorder that is characterized by a variety of heterogeneous phenotypes. Efforts to study FXS pathogenesis have been aided by the development and characterization of animal models of the disease. Research efforts in Drosophila melanogaster have revealed key insights into the mechanistic underpinnings of FXS. While much remains unknown, it is increasingly apparent that FXS involves a myriad of spatial and temporally specific alterations in cellular function. Consequently, the literature is filled with numerous discordant findings. Researchers and clinicians alike must be cognizant of this dissonance, as it will likely be important for the design of preclinical studies to assess the efficacy of therapeutic strategies to improve the lives of FXS patients.
\end{abstract}

\title{
Introduction:
}

Fragile $X$ syndrome (FXS) is the most prevalent heritable form of intellectual disability and a leading genetic cause of autism. In addition to cognitive and social impairments, Fragile $X$ patients present with behavioral symptoms including sleep disorders, attention deficit hyperactivity disorder (ADHD), and motor stereotypies. Several irregular physical features have also been observed in FXS patients such as altered facial structure, prominent ears, high-arched palate, hyperflexible joints, and macro-orchidism in post-pubertal males (Kidd et al., 2014). In a highly informative and comprehensive review, Kidd et al. (2014) discuss the current status of the clinical literature with regard to the prevalence of medical problems observed in FXS patients. Of note, FXS patients experience a spectrum of medical problems that likely occur due to connective tissue defects. These conditions include otitis media, ocular disorders, gastrointestinal disturbances, and growth problems (Kidd et al., 2014). The vast heterogeneity of phenotypes observed in affected individuals has made it difficult to precisely ascertain comorbid disorders in FXS. Discordant findings in clinical studies emphasize the variability of data obtained from human patients and suggest that selection bias and large differences in study design and data collection methods make it difficult to predict which of the associated medical problems physicians are most likely to encounter when treating FXS patients. Given the myriad of phenotypes that have been documented in the clinical literature, it has become increasingly apparent that FXS is a systemic disorder. Despite this evidence, the majority of research has been focused on the neurological aspects of FXS and many of the systemic phenotypes have been ignored. Consequently, a large gap has arisen between the observations in the clinic and the discoveries at the bench.

At the molecular level, FXS is caused by loss-of-function of the Fragile $X$ Mental Retardation 1 (Fmr1) gene. Typically this loss-of-function occurs due to an expansion of a trinucleotide repeat in the 5' untranslated region (UTR) of the Fmr1 gene (Verkerk et al., 1991). In affected individuals, this expansion contains over 200 repeats, which results in hypermethylation of the locus and subsequent transcriptional silencing of the gene (Fu et al., 1991; Pieretti et al., 1991). As such, this pathogenic mutation eliminates the expression of the product of the Fmr1 gene, termed Fragile X Mental Retardation Protein (FMRP). Many studies have demonstrated that FMRP is an RNA binding protein that is enriched in the nervous system (Ashley et al., 1993; Brown et al., 1998; Chen et al., 2003; Darnell et al., 2005; Siomi et al., 1993). It is estimated that FMRP binds to and regulates over 800 distinct mRNA targets (Darnell et al., 2011). Although FMRP is primarily thought to act as a translational repressor, it has been shown to promote translation in some cases (Bechara et al., 2009; Krueger et al., 2011; Monzo et al., 2006). Additionally, FMRP participates in several other pathways that are known to modulate gene expression. For example, it has been shown that FMRP stabilizes and assists the transport of mRNAs within the cell (Dictenberg et al., 2008; Zalfa et al., 2007). It has also been found to interact with components of the RNA interference, small interfering RNA, and microRNA pathways (Caudy et al., 
2002; Ishizuka et al., 2002; Jin et al., 2004). Taking the large number of putative mRNA targets along with evidence that FMRP is implicated in multiple aspects of gene regulation, it appears that while FXS is monogenic in nature, Fmr1 has pleiotropic effects that likely underlie the diversity of phenotypes observed in FXS patients.

Since the etiology of FXS is well characterized, researchers have been able to generate valuable animal models of the disease. These animal models are highly relevant on a translational level and facilitate an increased understanding of FXS pathogenesis because they allow researchers to control for genetic and environmental heterogeneity and thereby circumvent many of the limitations of human studies. With the advent of a wealth of genetic tools, Drosophila melanogaster has emerged as a highly tractable model for the study of FXS (Dockendorff et al., 2002; Inoue et al., 2002; Morales et al., 2002; Zhang et al., 2001). The Drosophila genome contains a single gene, dffmr1, whose product shares both sequence identity and biochemical properties with its mammalian ortholog (Wan et al., 2000). Much like its mammalian counterpart, dFMRP is an RNA-binding protein that has been shown to bind to select mRNA transcripts and repress their translation (Reeve et al., 2005; Zhang et al., 2001). Moreover, it has been demonstrated that the RNA binding affinity of dFMRP is highly conserved, which suggests that the RNA-binding profile of dFMRP may greatly resemble the list of mRNA targets bound by FMRP (Brown et al., 2001; Darnell et al., 2009; Darnell et al., 2011; Miyashiro et al., 2003). While only a handful of mRNA targets of dFMRP have been identified in Drosophila, the targets that have been validated encode proteins that function in cytoskeleton maintenance and larval crawling behavior (Lee et al., 2003; Reeve et al., 2005; Xu et al., 2004; Zhang et al., 2001). The products of these mRNA targets have functional properties that are very similar to those identified in the murine model of FXS (Castets et al., 2005; Lu et al., 2004). In addition to these genetic and functional similarities, flies that harbor loss-of-function mutations in the $d f m r 1$ gene recapitulate many of the characteristics of FXS (Table 1). Specifically, $d f m r 1$ null flies show defects in memory, social behavior, circadian rhythmicity, and sleep (Bolduc et al., 2008; Bushey et al., 2009; Dockendorff et al., 2002; Inoue et al., 2002; McBride et al., 2005; Morales et al., 2002). Further, $d f m r 1$ null flies exhibit defects in neural architecture that are reminiscent of the dendritic spine defects seen in both human patients and murine models of FXS (Comery et al., 1997; Dockendorff et al., 2002; Lee et al., 2003; Michel et al., 2004; Morales et al., 2002; Zhang et al., 2001). These robust correlates to mammalian phenotypes render the Drosophila model an ideal paradigm to study the cellular and molecular mechanisms involved in FXS pathogenesis and to ascertain the efficacy of novel therapeutic approaches.

Several recently published reviews elegantly summarize the current understanding of the molecular pathways that are altered in FXS and the corresponding molecular targets that have been identified for therapeutic intervention (Doll and Broadie, 2014; Lozano et al., 2014; Santos et al., 2014; Scharf et al., 2014). In this review, we discuss the diverse functions of dFMRP in neuronal circuits, behavioral output pathways, and the response to cellular stress. Recent work in the Drosophila model of FXS suggests that dFMRP plays an important role in the modulation of intracellular processes that are important for cellular stability and maintenance. Multiple lines of evidence suggest that dFMRP acts in a highly cell type-, temporal-, and pathway-specific manner. These findings, coupled with observations in murine models of FXS, provide a compelling case that future progress depends upon increased understanding of the spatiotemporal requirements for FMRP.

\section{Neuronal Circuits:}

\section{Neural Stem Cells}

The process of neurogenesis is critical for proper assembly of neural circuitry and the establishment of accurate brain connectivity. This intricate, highly orchestrated process is driven by the proliferation of stem cells and progenitor cells, which subsequently differentiate into neurons and glia. It 
is essential to achieve the correct balance between neurons and glia, as an incorrect ratio of neurons to glia promotes aberrant wiring of the brain. Importantly, Drosophila neuroblasts (NBs) follow general stem cell principles and employ conserved molecular pathways (Callan et al., 2010; Callan and Zarnescu, 2011). As such, NBs have emerged as a valuable model to study stem cell proliferation and differentiation during development. Callan et al. (2010) utilized the wealth of genetic tools available in Drosophila to elucidate the role of dFMRP during early neurogenesis in vivo. The results of their loss of function studies and clonal analyses in larval NBs suggest that dFMRP is required during early stages of development before synaptogenesis occurs. Loss of dFMRP was found to increase the proliferative capacity of larval NBs and promote the generation of supernumerary neurons that survive into adulthood. Moreover, these studies revealed that larval NBs lacking dFMRP exit quiescence prematurely and proliferate sooner than their wild-type counterparts. However, this enhanced early proliferation is followed by a deceleration of proliferation later in development. This important discovery provided the first evidence that dFMRP modulates proliferation in larval NBs by regulating the time at which neural progenitors exit quiescence. In a subsequent publication, Callan et al. (2012) expanded upon these findings and utilized tissue specific RNA interference to elucidate the spatiotemporal role of dFMRP during larval brain development. Their observations suggest that there is heterogeneity in the temporal requirement for $\mathrm{dFMRP}$ such that $\mathrm{dFMRP}$ regulation is required during distinct developmental windows in different cell types. Specifically, dFMRP appears to be required first in NBs and subsequently in glia to control exit from quiescence. Importantly, this is the first study to assert that dFMRP functions to regulate NB reactivation in glial cells in vivo. To address the mechanism by which dFMRP regulates the timing of NB reactivation, Callan et al. (2012) monitored components of the insulin signaling pathway, as this pathway has been shown to modulate neurogenesis (Chell and Brand, 2010; Sousa-Nunes et al., 2011). Callan et al. (2012) showed that elevations of pAkt in the larval brain are concurrent with the developmental window during which dFMRP is required in glial cells. They also demonstrated that $d f m r 1$ genetically interacts with $d F o x O$, a key transcriptional regulator of insulin signaling. Together, these results suggest that the interplay between dFMRP and the insulin signaling pathway modulates NB reactivation in vivo. The complexity of the results from these Drosophila studies provide strong evidence that dFMRP plays distinct, cell type-specific roles during different developmental time points in vivo. This conclusion emphasizes the need for members of the field to be cognizant of the spatial and temporal context in which studies are conducted to gain a better understanding of the molecular underpinnings of FXS disease pathology.

Consistent with observations in Drosophila, studies in mice have shown that FMRP regulates the timing and proliferation of neural stem and progenitor cells and that it is required to generate appropriate numbers of neurons and glia (Guo et al., 2011; Luo et al., 2010; Saffary and Xie, 2011). Much like Drosophila larval NBs, one such study used a combination of in vitro and in vivo approaches to assess the effect of FMRP deficiency on adult neurogenesis in the mammalian hippocampus (Luo et al., 2010). The results from experiments conducted in cultured explants of mouse adult neural progenitor cells (aNPCs) and in vivo monitoring of endogenous mouse aNPCs suggest that proliferation is augmented in Fmr1 knockout aNPCs. Moreover, loss of FMRP alters aNPC fate specification such that Fmr1 knockout aNPCs exhibit decreased neuronal differentiation and increased glial differentiation. Additional experiments revealed that FMRP regulates the expression of proteins involved in cell cycle progression as well as GSK3 $\beta$, a key component of the Wnt signaling pathway. Based on these and other mechanistic findings, Luo et al. (2010) hypothesize that Fmr1 deficiency results in dysregulation of the Wnt signaling pathway and thereby alters the proliferative capacity and fate specification of mouse aNPCs. Moreover, loss-of-function studies in the neocortex of mouse embryos suggest that FMRP suppresses the transition from stem-cell like radial glial cells (RGCs) to intermediate progenitor cells (IPCS) in a time dependent manner (Saffary and Xie, 2011). This result is consistent with the observation that dFMRP is important in the early stages of neurogenesis in Drosophila (Callan et al., 2010). However, 
the results in Luo et al. (2010) indicate that loss of Fmr1 depletes the population of RGCs, which is the opposite of what is seen in Drosophila larval NBs and mouse aNPCs (Callan et al., 2010). This discrepancy is likely due to differences in neural stem cell proliferation in different tissues at different times.

From a behavioral standpoint, ablation of FMRP and the consequent alterations in hippocampal neurogenesis result in impaired performance in two different hippocampus-dependent learning paradigms. However, selective restoration of FMRP in aNSCs rescues the cellular and behavioral phenotypes that occur in Fmr1 knockout mice (Guo et al., 2011). It is possible that GSK3 $\beta$ hyperactivity modulates these phenotypes, as pharmacological treatment with a highly specific GSK3 $\beta$ inhibitor ameliorates aberrant cell fate specification, enhances the integration of newborn neurons into circuits, and rescues impairments in hippocampus-dependent learning in Fmr1 KO mice (Guo et al., 2012).

Despite the differences inherent to each model system, it is clear that findings in the literature converge on a common notion that the role of FMRP in neurogenesis is diverse and tightly regulated at different time points and in different cellular populations. There appears to be a shared theme of overproliferation and differentiation defects in neural stem and progenitor cells in the absence of FMRP (Callan et al., 2010; Guo et al., 2011; Luo et al., 2010; Saffary and Xie, 2011). The observation that FMRP regulates neurogenesis in aNPCs by controlling the production of neurons and glia underscores the important role that FMRP plays in the establishment of proper neural circuitry and accurate connectivity. The findings by Guo et al. (2011) that loss of FMRP in aNPCs results in learning deficits that can be rescued by restoration of FMRP in this cell population provide further support for the hypothesis that loss of FMRP can result in aberrant connections that are detrimental to behavioral and cognitive output. From a therapeutic perspective, recent findings in Drosophila and mice have uncovered novel targets that have the potential to benefit patients and have identified critical time points during which intervention might be most efficacious.

\section{Cytoskeleton and neural architecture}

FMRP plays an important role in the establishment and maintenance of intracellular microtubule and actin scaffolds. Previous reports have demonstrated that FMRP represses the translation of microtubule associated protein 1B (MAP1B) in both flies and mice (Lu et al., 2004; Zhang et al., 2001). Additionally, FMRP has been shown to associate with components of kinesin and dynein to regulate mRNA trafficking along microtubules (Dictenberg et al., 2008; Estes et al., 2008; Ling et al., 2004). More recently, dfmr1 was shown to genetically interact with the spastin gene, which encodes a microtubule severing protein (Yao et al., 2011). Under normal conditions, spastin promotes the proper assembly of neuronal microtubules to ensure appropriate synaptic growth (Trotta et al., 2004). The interaction between dfmr1 and spastin is essential because it enables migration of mitochondria along microtubules (Yao et al., 2011). Outside of the nervous system, dFMRP facilitates the organization of microtubules in peripheral tissues. As such, loss of $d f m r 1$ expression in the germline alters the configuration of microtubules in spermatozoa and likely contributes to the infertility observed in dfmr1 null males (Zhang et al., 2004).

Analogous to what is observed in the case of microtubule organization, normal $d f m r 1$ expression is also critical for maintenance of the actin cytoskeleton. It has long been known that dFMRP binds to and represses the translation of chickadee, which is the Drosophila homolog of profilin (Reeve et al., 2005). This finding is particularly intriguing because the protein encoded by chickadee binds to actin. In a recent study, dfmr1 was also shown to interact with cheerio, the Drosophila homolog of filamin $A$ (Bolduc et al., 2010a). Since cheerio is important for remodeling of the actin cytoskeleton, the results from the studies conducted by Reeve et al. (2005) and Bolduc et al. (2010a) suggest that actin dynamics are altered in dfmr1 null flies. These molecular changes in actin dynamics appear to affect behavior and cognition, as flies that are heterozygous for loss-of-function mutations in cheerio and $d f m r 1$ have impaired olfactory long-term memory (Bolduc et al., 2010a). To complement this behavioral data, 
Bolduc et al. (2010a) present molecular evidence that cheerio expression is lower in $d f m r 1$ null flies than in wild-type counterparts after training in a memory paradigm. The observed changes in the maintenance of the actin cytoskeleton in the Drosophila model of FXS are also present in murine models of the disease, as Fmr1 knockout mice exhibit impaired phosphorylation of p-21-activated kinase (PAK) and subsequent delayed stabilization of newly formed actin filaments in response to theta burst afferent stimulation (Chen et al., 2010). These results are relevant from a therapeutic standpoint because genetic and pharmacological inhibition of PAK has been shown to mitigate audiogenic seizures and hyperactivity in Fmr1 knockout mice (Dolan et al., 2013; Hayashi et al., 2007). Together, these discoveries suggest that improper regulation of the actin cytoskeleton is likely one mechanism by which the absence of FMRP results in aberrant behavior and cognition.

Along with cytoskeletal defects, $d f m r 1$ null flies also have aberrations in neural architecture. In the central nervous system (CNS), overelaborated branching has been observed in the small ventral lateral neurons (sLNvs), which constitute the component of the central circadian clock that drives circadian rhythms in free-running conditions in Drosophila (Dockendorff et al., 2002; Gatto and Broadie, 2009; Morales et al., 2002). Additionally, the architecture of the Mushroom Bodies (MBs), which constitute the primary learning and memory center of the fly brain, cross over the midline and exhibit varying levels of fusion (Michel et al., 2004; Reeve et al., 2005).

To expand upon these behavioral and neuroanatomical findings, subsequent studies utilized a variety of genetic and pharmacological manipulations to demonstrate that inhibition of matrix metalloproteinase (MMP), an enzyme that is important for remodeling of the extracellular matrix, rescues the observed morphological defects in the sLNVs and MBs (Siller and Broadie, 2011). Since dfmr1 null flies also exhibit architectural defects in the neuromuscular junction (NMJ) (Zhang et al., 2001), Siller and Broadie (2011) expanded upon their findings in the CNS and examined the effect of treatment with minocycline, an MMP inhibitor, on peripheral motor structural changes. While this manipulation did ameliorate structural alterations in NMJs, the NMJ phenotype was less sensitive to minocycline dosage than the alterations in the CNS. Together these results indicate that central and peripheral neurons respond differently to drug treatment (Siller and Broadie, 2011). Similarly, studies in Fmr1 knockout mice indicate that mmp9 mRNA co-localizes with FMRP both at the synapse and in dendrites (Janusz et al., 2013). The observed co-localization likely has functional relevance, as treatment with minocycline or genetic reduction of MMP9 rescues dendritic spine defects and aberrant behavior in Fmr1 knockout mice (Bilousova et al., 2009; Sidhu et al., 2014). Compellingly, treatment of FXS patients with minocycline showed some improvements in both mood and anxiety, indicating that the positive effects of minocycline observed in the fly and mouse models may translate to the clinic (Leigh et al., 2013; Paribello et al., 2010).

Clearly the study of disruptions in the neural architecture of the SLNvs, MBs and NMJs has yielded promising insight into the ways in which the loss of dFMRP affects neuron morphology. However, the role of dFMRP extends beyond regulation of neural branching. Specifically, a novel phenotype has been identified in a subset of the pigment dispersing factor (PDF)-positive neurons located in the tritocerebrum, known as the PDF-TRI cells. While these neurons normally undergo apoptosis within two days of eclosion (Gatto and Broadie, 2011; Renn et al., 1999), experimental results indicate that the PDF-TRI cells fail to properly undergo apoptosis in dfmr1 null flies (Gatto and Broadie, 2011). Further, another class of neurons entitled the crustacean cardioactive peptide (CCAP) peptidergic neurons exhibit delayed clearance in dfmr1 null flies (Gatto and Broadie, 2011). Thus, these findings highlight a critical role for dFMRP in the spatiotemporal regulation of apoptosis in the CNS. Although the functional implications of the ectopic persistence of these neurons are yet to be determined, these findings highlight another mechanism by which loss of dFMRP disrupts neural architecture. These results suggest that further exploration of the mechanism by which FMRP influences synaptic architecture and 
the resultant functional consequences that occur in the absence of FMRP may reveal promising, novel targets for therapeutic intervention.

\section{Inhibitory Circuit}

At the circuit level, multiple studies have shown that the excitatory/inhibitory (E/I) balance is perturbed in FXS neuronal networks (Cea-Del Rio and Huntsman, 2014; Doll and Broadie, 2014; Gatto and Broadie, 2010). Since the correct E/I balance is critical for proper maintenance of neuronal networks, several groups have postulated that E/I imbalance in the circuitry of CNS might underlie many of the observed deficits in FXS. Recent work in the Drosophila model system has broadened our understanding of how inhibitory and excitatory neural circuits contribute to FXS disease pathogenesis.

One factor that has been implicated in circuit dysfunction in FXS is altered inhibitory GABAergic neurotransmission (Cea-Del Rio and Huntsman, 2014; Doll and Broadie, 2014; Paluszkiewicz et al., 2011). While the theory that hypoinhibiton is a causal factor in FXS has garnered much appreciation, the field has been stymied by seemingly contradictory results regarding alterations observed in GABAergic signaling in animal models of FXS. Fortunately, recent advances in Drosophila genetics have rendered the fly model of FXS a particularly useful tool to assay GABAergic circuitry.

Drosophila researchers pioneered the notion that GABA has therapeutic potential for FXS following the result of a high throughput chemical screen to identify compounds that rescued excess dietary glutamate-induced lethality in $d f m r 1$ null flies. Strikingly, in addition to preventing lethality, pharmacological treatment with GABA or GABA reuptake inhibitors was able to rescue neuroanatomical defects, excess futsch translation, and abnormal naïve courtship behavior in dfmr1 null flies (Chang et al., 2008). Despite these promising initial observations, recent research suggests that pharmacological augmentation of GABAergic signaling alone is not sufficient to restore MB-dependent olfactory learning deficits (Gatto et al., 2014). Close examination of GABAergic circuitry in the MB identified several molecular changes that arise in the absence of dFMRP (Gatto et al., 2014). Specifically, the $d f m r 1$ null flies have reduced expression of $\mathrm{GABA}_{A}$ receptor subunits as well as decreased levels of the rate-limiting enzyme involved in GABA synthesis, glutamic acid decarboxylase (GAD). From a functional standpoint, Gatto et al. (2014) found that calcium signaling and kinetics in response to acute depolarization are altered in the inhibitory neurons of the MB in dfmr1 null flies. Moreover, the GABAergic neurons that innervate the $\mathrm{MB}$ exhibit aberrant architectural development. Interestingly, the developmental trajectory of these neurons is defined by underdevelopment at earlier stages that is subsequently followed by overelaboration. Gatto et al. (2014) noted that they observe undergrowth in these inhibitory MB cells at the same time that overgrowth has been reported in excitatory MB cells (Siller and Broadie, 2011). Based on this contrast, Gatto et al. (2014) postulate that dFMRP may play different roles in inhibitory versus excitatory MB cell populations. This possibility suggests that dFMRP function is exquisitely cell-type specific.

The notion that GABAergic circuit function in the CNS may not be uniform has also been noted in murine models of FXS. At the molecular level, there appear to be brain region specific alterations in the levels of GABA receptor subunits as well as in enzymes involved in GABA synthesis, transport, and catabolism in Fmr1 knockout mice (Adusei et al., 2010; D'Hulst et al., 2009; El Idrissi et al., 2005; OlmosSerrano et al., 2010; Paluszkiewicz et al., 2011). These changes include an apparent decrease in the levels of GAD and vesicular GABA in the amygdala of Fmr1 knockout mice (Olmos-Serrano et al., 2010). In contrast, increases in the levels of GAD and the $\beta$-subunit of the GABA receptor have been observed in the cortex, hippocampus, brainstem, and diencephalon of Fmr1 knockout mice (El Idrissi et al., 2005). In addition to these regional differences, $\mathrm{GABA}_{\mathrm{A}}$ receptor subunits and GABA enzymes demonstrate extremely dynamic and complex changes in their expression profiles at different times during 
development in Fmr1 knockout mice (Adusei et al., 2010). From a behavioral standpoint, treatment with $\mathrm{GABA}_{\mathrm{A}}$ receptor agonists has been shown to decrease the incidence of audiogenic seizures in Fmr1 knockout mice (Darnell and Klann, 2013; Heulens et al., 2012). Similarly, treatment with arbaclofen, a $G_{A B A}$ receptor agonist, was shown to correct exaggerated protein synthesis, reduce susceptibility to audiogenic seizures, and normalize repetitive behavior in the murine model of FXS (Darnell and Klann, 2013; Henderson et al., 2012). However, it has been shown that while pharmacological administration of a $\mathrm{GABA}_{\mathrm{A}}$ receptor agonist ameliorates excitability deficits in the amygdala, hyperactivity, and deficits in pre-pulse inhibition, this manipulation exacerbates cued fear and startle responses (Olmos-Serrano et al., 2011). Given these findings it appears that from a therapeutic perspective GABA receptor agonists are potentially advantageous in some contexts, but that they are by no means a panacea. Additional studies must be conducted to ascertain the precise spatiotemporal role of FMRP in GABAergic circuitry in order to identify whether this is a viable intervention strategy and, if so, which patients are the best candidates for treatment with these compounds.

\section{Excitatory Circuit}

Much like the extensive literature on inhibitory circuits, it is widely appreciated that FMRP is important in excitatory circuits. It is primarily thought that FMRP modulates excitatory circuits through its relationship with metabotropic glutamate receptors (mGluRs). A prevalent hypothesis in the field suggests that the mGluR pathway is hyperactive in FXS (Bear et al., 2004). Consistent with this theory, it has been shown that inhibition of the mGluR pathway rescues behavioral and anatomical phenotypes in both fly and mouse models of FXS (Dolen et al., 2007; McBride et al., 2005; Michalon et al., 2012; Yan et al., 2005).

Lately, the focus of the field has shifted towards the study of several other signaling pathways that are dysregulated in FXS. Many recent studies have sought to assess the interplay between these pathways, particularly the way in which molecules that participate in multiple signaling pathways contribute to the observed behavioral and cognitive deficits. One such study in the Drosophila model of FXS indicates that while mGluR antagonists rescue an age-onset defect in a social learning paradigm, this deficit was also rescued by lithium, a known direct and indirect inhibitor of Glycogen Synthase Kinase-3 (GSK-3) (Choi et al., 2010). Lithium was previously identified as a compound of interest when it was shown to rescue short-term memory deficits in dfmr1 null flies (McBride et al., 2005). Subsequent studies in murine models of FXS provide additional evidence that GSK-3 is hyperactive in the disease state and suggest that the observed dysregulation of GSK-3 is likely caused by decreased levels of inhibitory phosphorylation at a conserved residue (Yuskaitis et al., 2010). A recent study that probed the interaction between the mGluR pathway and the GSK-3 pathway found that inhibition of mGluR5 resulted in increased inhibitory phosphorylation of GSK-3 (Yuskaitis et al., 2010). This finding suggests that the observed excess in glutamatergic signaling might be linked to GSK-3 hyperactivity. Notably, another group found that treatment of Fmr1 knockout mice with highly specific pharmacological inhibitors of GSK-3 normalized multiple phenotypes that appear to be resistant to pharmacological inhibition of the mGluR pathway (Franklin et al., 2014). The dichotomy between the observations in Yuskaitis et al. (2010) and Franklin et al. (2014) indicates that the mGluR and GSK-3 pathways collaborate in some, but not all situations to promote normal behavior.

The field must remain cognizant that mGluR inhibitors do not rescue all of the phenotypes observed in animal models of FXS. Studies in dfmr1 null flies suggest that pharmacological treatment with mGluR inhibitors does not ameliorate irregular grooming patterns, arrhythmic circadian behavior, and increased sleep (Bushey et al., 2009; McBride et al., 2005; Tauber et al., 2011). Similarly, it has been shown that inhibition of the mGluR pathway does not rescue macro-orchidism in the murine model of FXS (Dolen et al., 2007). Taken together, these results indicate that while increased activity of the mGluR pathway is involved in FXS, this disease is not solely a product of mGluR hyperactivation. Instead 
the dysregulation of and complex interactions between multiple signaling pathways underlie FXS pathogenesis.

\section{Peripheral Motor Output Pathways}

While much emphasis has been placed on understanding the role of FMRP in the CNS, many studies have demonstrated that FMRP is also important in peripheral motor output pathways. In Drosophila, the larval NMJ has been established as a highly tractable, well-defined system for the study of synaptic structure and function in a peripheral motor context. It is widely appreciated that loss of dFMRP results in robust NMJ phenotypes including synaptic overgrowth and altered neurotransmission (Zhang et al., 2001). However, the precise mechanistic underpinnings of these defects remain largely unknown. Recently, research in $d f m r 1$ null flies has greatly expanded our understanding of how dFMRP involvement in post-transcriptional gene regulation as well as in cascades that govern trans-synaptic signaling is critical for proper synaptic structure and function (Bhogal et al., 2011; Friedman et al., 2013; Xu et al., 2013).

In addition to its predicted function as a translational regulator, FMRP has also been shown to modulate other aspects of RNA biology (Bhogal et al., 2011; Xu et al., 2013). An elegant series of biochemical and genetic experiments revealed that dFMRP acts in the RNA editing system to regulate synaptic architecture (Bhogal et al., 2011). Specifically, Bhogal et al. (2011) demonstrated that dFMRP and Drosophila adenosine deaminase acting on RNA (dADAR) biochemically interact. To probe the physiological relevance of this interaction in vivo, genetic epistasis experiments were conducted in flies with loss-of-function mutations in both $d f m r 1$ and $d A d a r$. Since the phenotypes associated with each single mutant are distinct, analysis of double mutant flies allowed Bhogal et al. (2011) to ascertain that dFMRP acts upstream of dADAR in a common pathway responsible for the establishment of NMJ morphology. Examination of editing in several candidate transcripts revealed that RNA editing was in fact altered in $d f m r 1$ null flies, indicating that the interaction between dFMRP and dADAR has functional consequences (Bhogal et al., 2011). Further work will be necessary to determine if RNA editing is similarly affected in Fmr1 knockout mice and human patients (Bassell, 2011). Importantly, this study was the first to identify an interaction between a disease-associated protein and a protein involved in Adenosine-to-Inosine RNA editing.

Similarly, dFMRP has been shown to biochemically and genetically interact with Drosophila topoisomerase $3 \beta$ (dTop3 $\beta$ ) and Drosophila Tudor domain-containing protein 3 (dTDRD3) in a complex that is conserved in mammals ( $X u$ et al., 2013). Like dFMRP, both dTop3 $\beta$ and dTDRD3 associate with mRNA (Linder et al., 2008; Xu et al., 2013). To evaluate the function of the resultant protein complex in vivo, Xu et al. (2013) examined phenotypes generated in the Drosophila eye and NMJ in response to manipulation of the corresponding genes. Based on the results of genetic epistasis experiments, $\mathrm{Xu}$ et al. (2013) concluded that $d T o p 3 \beta$ and $d f m r 1$ functionally antagonize each other to regulate eye development and NMJ formation. Notably, this result is reminiscent of the genetic interaction that Bhogal et al. (2011) observed between dfmr1 and dAdar. In contrast, the other member of this complex, dTDRD3, appeared to have a positive effect on dFMRP function in the Drosophila eye. The opposing roles that dTop3 $\beta$ and dTDRD3 play with respect to eye development suggest that these proteins may have an antagonistic relationship in this context. Together, these findings reveal that the interaction between dFMRP, dTop3 $\beta$, and dTDRD3 is incredibly cell-type specific. In addition to cell-type specificity, (Xu et al., 2013) demonstrated that the functional relationship between dFMRP and dTop3 $\beta$ is distinct at the level of gene regulation. Contrary to the observed negative interaction between dFMRP and dTop3 $\beta$ in eye development and overall NMJ architecture, these proteins were show to operate coordinately to promote the expression of a common target, ptk2, in NMJs. As such, it is possible that dFMRP may antagonize dTop3 $\beta$ function on certain mRNAs and facilitate its action on other mRNAs to regulate gene expression at the synapse. To further illustrate the importance of Top3 $\beta$ in synapse 
formation, Xu et al. (2013) cultured and stained primary cortical neurons from Top3 $\beta$ knockout mice and showed that synapse formation is altered in these animals. The discovery of these novel roles for FMRP in synaptogenesis greatly expands our understanding of FMRP function. However, the evidence for seemingly contradictory functions of FMRP in different contexts leaves the field with more questions than answers. It has become increasingly evident that to gain a better grasp of FXS pathogenesis the field needs to delve deeper into the mechanistic underpinnings of the divergent actions of FMRP.

One approach that addresses the nuances of FMRP function is a shift in focus from cellautonomous to non-cell autonomous roles of FMRP. Several studies have elucidated both pre- and postsynaptic requirements for FMRP (Gatto and Broadie, 2008; Schreiner et al., 2012). As such, examination of the extracellular synaptomatrix and the relevant trans-synaptic signaling pathways in $d f m r 1$ null flies has provided a broader view of how FMRP acts on both sides of the synaptic cleft to impact neural architecture (Friedman et al., 2013). Several lines of evidence suggest that dysregulation of a class of membrane-bound proteins that bind ligands proximal to the cell surface to modulate downstream signaling pathways, collectively entitled heparin sulfate proteoglycans (HSPGs), might underlie the aberrant synaptogenesis present in FXS. Central to this hypothesis, FMRP has been shown to bind to HSPG mRNA directly (Darnell et al., 2011). To test whether the absence of FMRP impacts HSPG levels and consequentially alters downstream trans-synaptic signaling, Friedman et al. (2013) conducted a series of experiments to evaluate the effect of genetic manipulation of these factors on NMJ structure and function. First, Friedman et al. (2013) demonstrated that the synaptic HSPG co-receptors, Dally-like protein (Dlp) and Syndecan (Sdc), are upregulated in the NMJs of $d f m r 1$ null flies. Next, they established that in the absence of dFMRP, trans-synaptic signaling was depressed in two parallel anterograde pathways that are regulated by the presynaptic ligands Wingless (Wg) and Jelly belly (Jeb). The altered abundance of $\mathrm{Wg}$ and Jeb in $\mathrm{dfmr} 1$ null flies resulted in reduced downstream signaling in postsynaptic muscle nuclei. In contrast, retrograde BMP signaling was not impaired in dfmr1 null flies. Taken together, these results suggest that dFMRP specifically alters anterograde trans-synaptic signaling pathways. To validate the functional consequences of HSPG co-receptor overexpression on synaptic morphology and function, Friedman et al. (2013) genetically reduced HSPG co-receptor expression in the dfmr1 null background. As expected, correction of HSPG co-receptor overabundance was sufficient to normalize synaptic overelaboration and mitigate elevations of neurotransmission in dfmr1 null NMJs. Moreover, this genetic manipulation restored the observed reductions in Wg and Jeb signaling to wildtype levels. These findings suggest a model in which dFMRP negatively regulates HSPG co-receptor levels during synaptogenesis at the Drosophila NMJ. FMRP then functions in a non-cell autonomous manner to modulate anterograde trans-synaptic signaling pathways and thereby ensure proper synaptic morphology and function. While these findings in the Drosophila model of FXS provide the first mechanistic evidence that aberrant trans-synaptic signaling is a causal factor in FXS pathogenesis, the functions of the extracellular synaptomatrix in structural and functional maturation of synapses are conserved in mammals (Friedman et al., 2013). Thus, it will be important to determine whether these promising observations in the Drosophila model of FXS can be replicated in mammalian FXS models, as further investigation of trans-synaptic signaling might have great translational relevance and provide clinicians with additional therapeutic strategies to treat FXS.

\section{Behavioral Output Pathways}

\section{Social Interaction and Memory}

In accordance with the array of neuronal aberrations that occur in the absence of dFMRP, dfmr 1

null flies exhibit abnormal behavior and cognition. Importantly, the behavioral and cognitive deficits observed in the Drosophila model of FXS are reminiscent of the symptoms seen in human patients (Bolduc et al., 2008; Dockendorff et al., 2002; McBride et al., 2005). While at a superficial level it seems 
that alterations in neural circuitry are causative of the observed behavioral and cognitive defects, evidence suggests that this view is oversimplified. Rather, there are instances in which therapeutic interventions remedy behavioral but not neuroanatomical phenotypes in dfmr1 null flies (McBride et al., 2005).

One behavior that is altered in $d f m r 1$ null flies is courtship. An innate social program exists in Drosophila in which male flies court female flies using a stereotypical sequence of behaviors (Greenspan and Ferveur, 2000). When a female fly is receptive to the advances of a male fly, the male typically remains engaged in the courtship ritual until copulation is achieved. In contrast, $d f m r 1$ null males quickly lose interest in social interaction with females in this courtship paradigm. As a result, dfmr1 null flies exhibit an overall decrease courtship levels and fail to proceed to the latter, more advanced stages of the courtship ritual (Dockendorff et al., 2002). Consistent with these observations, novel findings presented in Bolduc et al. (2010b), indicate that $d f m r 1$ null flies have an additional deficit in social interaction. Specifically, the authors found that $d f m r 1$ null flies in a chamber are less likely to interact with conspecifics placed in an adjacent chamber than their wild-type counterparts (Bolduc et al., 2010b).

In addition to the observed social deficits, dfmr1 null flies exhibit memory impairments as assessed using both odor-based classical and courtship-based conditioning paradigms. The basic premise of odor-based classical conditioning is that adult flies are exposed to two odors, one of which is paired with an electrical shock. After a training period, flies are queried for their ability to remember which of the two odors was associated with the aversive stimulus during the training phase(Tully and Quinn, 1985). In courtship-based testing, adult males are paired with an unreceptive female during training and are subsequently tested for a reduction in courtship amount when paired with a receptive female. It is thought that the suppression of courtship amount during the testing phase indicates that the male fly remembers the negative experience with an unreceptive female during training (Siegel and Hall, 1979). The length of time between the training and testing phases varies based upon the type of memory that is being assessed. Many studies that employed these memory assays found that $d f m r 1$ null flies exhibit deficits in immediate recall-, short-term-, and long-term memory (Banerjee et al., 2010; McBride et al., 2005). However, it should be noted that some manipulations that were found to ameliorate the observed memory deficits did not normalize defects in MB architecture (McBride et al., 2005). Further, it appears that the requirement for $d f m r 1$ expression varies in subsets of neurons that comprise the MB. Specifically, concurrent $d f m r 1$ expression in the $\alpha, \beta$, and $\gamma$ lobes of the MB in a genetic background that is otherwise $d f m r 1$ null is sufficient to rescue olfactory learning defects. In contrast, restoration of $d f m r 1$ expression in the $\gamma$ lobes of the MB alone or in the ellipsoid body alone is not sufficient to rescue the observed olfactory learning defect (Kanellopoulos et al., 2012). Similarly, genetic knock down of dfmr1 expression in the $\alpha$ and $\beta$ lobes of the MB was detrimental to learning, whereas genetic knock down $d f m r 1$ expression in the $\gamma$ lobes of the MB or ellipsoid body had no negative effect on learning (Kanellopoulos et al., 2012). Thus it is likely that multiple cell type-specific requirements for $d f m r 1$ expression converge to regulate behavioral and cognitive output.

Studies of behavior and cognition in the Drosophila model of FXS have also allowed for the identification of signaling molecules that are dysregulated in the disease state. The results of these studies are highly relevant at the translational level, as they uncover novel target for therapeutic intervention. One molecule that has recently been implicated in FXS pathogenesis is cyclic AMP (CAMP). Multiple lines of evidences indicate that CAMP levels are decreased in the absence of dFMRP and that that the circadian oscillation of CAMP response element binding protein (CREB) is dampened in dfmr1 null flies (Dockendorff et al., 2002; Kelley et al., 2007). These pioneering studies prompted exploration of the therapeutic potential of pharmacological augmentation of cAMP levels. As predicted, experiments in both the Drosophila and murine models of FXS demonstrated that treatment with Rolipram, a Phosphodiesterase-4 (PDE-4) inhibitor, pharmacologically restored cAMP levels and rescued deficits in associative learning, memory, and mGluR-dependent long term depression (Choi et al., 2015; 
Kanellopoulos,etal.,2012).

\section{Circadian Rhythms and Sleep:}

Although dfmr1 null flies display normal entrainment and circadian behavior in the presence of light cues, they are unable to maintain a free-running circadian rhythm in complete darkness (Dockendorff et al., 2002; Inoue et al., 2002; Morales et al., 2002). Despite this robust behavioral phenotype, the circadian clock in the CNS appears to function normally in $d f m r 1$ null flies. Thus it is likely that the observed behavior results from a defect in the circadian output pathway (Dockendorff et al., 2002; Inoue et al., 2002). With the advent of increasingly nuanced genetic tools and high-resolution technology, researchers have begun to elucidate the mechanism by which circadian behavior is altered in $d f m r 1$ null flies.

Consistent with the observed arrhythmic behavior in the absence of light cues, circadian gene expression is altered in $d f m r 1$ null flies (Xu et al., 2012). In addition to differences in mRNA levels, the expression and processing of several miRNAs appear to be altered in a circadian manner in dfmr1 null flies (Xu et al., 2012). This finding is particularly interesting because it suggests that the interaction between dFMRP and the miRNA pathway functionally impacts circadian regulation of gene expression. In addition to defective circadian behavior, evidence suggests that $d f m r 1$ null flies have altered sleep profiles. Specifically, $d f m r 1$ null flies have been shown to sleep longer than their wild-type counterparts (Bushey et al., 2009). The observed increase is total sleep appears to be largely due to a higher frequency of sleep episodes and occurs both in the presence and absence of light: dark cues, indicating that it is mechanistically distinct from the circadian phenotype (Bushey et al., 2009). Moreover, $d f m r 1$ null flies exhibit augmented resistance to arousal (Bushey et al., 2009; van Alphen et al., 2013). At the molecular level, sleep deprivation results in increased levels of dFMRP (Bushey et al., 2009). Structurally, dFMRP has been shown to regulate the pruning of synaptic branches in response to sleep (Bushey et al., 2011). These results indicate that proper $d f m r 1$ expression plays a critical role in maintaining sleep levels and sleep-dependent synaptic homeostasis.

Notably, the symptoms reported in children with FXS appear to contradict the sleep phenotype observed in dfmr1 null flies. For example, caregiver reports indicate that FXS patients have difficulty falling and asleep have frequent episodes of arousal during the night (Gould et al., 2000; Kronk et al., 2010; Kronk et al., 2009). In contrast, it has been reported that FXS patients have relatively increased levels melatonin, a sleep-promoting hormone, throughout the circadian period. (Gould et al., 2000). It is possible that these seemingly incompatible phenotypes can be explained by other medical problems such as sleep apnea, which appears to co-occur with sleeping difficulties in FXS patients (Kronk et al., 2010; Kronk et al., 2009). Such contradictory results emphasize the limitations of subjective, selfreported phenotypic measures and the urgent need for the discovery of biomarkers, which would provide tools for more objective assessments. Moreover, they highlight the necessity for more comprehensive studies of the FXS population to determine the prevalence of such disturbances.

\section{Response to Stress}

\section{DNA Damage Response}

Recently, it has been shown that dFMRP plays a role in the cellular response to DNA damage. Phenotypic evidence suggests that $d f m r 1$ null flies are more susceptible to irradiation or mutageninduced genotoxic stress than their wild-type counterparts. Moreover, in the absence of dFMRP, larval brain cells fail to arrest at the G2/M checkpoint in response to DNA damage. It is possible that this improper response is due in part to increased levels of cyclin B in dfmr1 null flies (Liu et al., 2012). Further evidence that dFMRP functions in the nuclear response to DNA damage comes from a recent study that demonstrated that damage induced by UV irradiation and pharmacological treatment with mutagenic compounds leads to increased nuclear localization of dFMRP and a greater amount of 
chromatin bound by dFMRP (Zhang et al., 2014). Consistent with these findings, dfmr1 null flies have little to no phosphorylation of H2AV, which is the Drosophila form of the mammalian histone variant $\mathrm{H} 2 \mathrm{AX}$. Loss of H2AV phosphorylation is particularly deleterious because when double-stranded breaks are induced in DNA, H2AV is activated by phosphorylation and proceeds to mediate the cellular response to DNA damage (Zhang et al., 2014). Much like what is observed in Drosophila, FMRP binds to chromatin and regulates $\mathrm{H} 2 \mathrm{AX}$ phosphorylation in response to DNA in mammalian models (Alpatov et al., 2014). Interestingly, the prevalence of cancer appears to be decreased in FXS patients (SchultzPedersen et al., 2001; Sund et al., 2009). Conversely, increased Fmr1 expression has been correlated with increased tumor metastasis (Luca et al., 2013). Since experimental evidence suggests that FMRP plays a role in the regulation of the DNA damage response and cancer susceptibility, these recently discovered functions of FMRP merit further exploration.

\section{Stress Granules}

Several studies in mice have demonstrated that FMRP recruits mRNA into stress granules (SGs), which are foci for translational repression in response to cellular stress (Kim et al., 2006; Mazroui et al., 2002). However, these studies did not assess whether FMRP is critical for the formation of SGs. This question was addressed in a recent study in a Drosophila cell based model. The authors found that much like its mammalian ortholog, dFMRP is also recruited into SGs upon heat shock or other forms of cellular stress (Gareau et al., 2013). While it appears that dFMRP is dispensable for SG formation, Gareau et al. (2013) revealed that dFMRP shuttles in and out of SGs and identified the motifs in dFMRP that are important for these shuttling dynamics. This finding is exciting, as this is the first report of a protein that shuttles between RNA localized in SGs and the cytosol.

\section{Conclusion:}

Although disheartening, recent studies highlight the notion that dFMRP functions in an exquisitely cell type- and temporal-specific manner. Therefore it is likely that apparent contradictions in the literature reflect the heterogeneity of dFMRP function in different spatiotemporal contexts. Nevertheless, several exciting new discoveries in Drosophila and murine models of FXS have exposed nuances in FMRP activity. In a broad sense, studies in the CNS of $d f m r 1$ null flies revealed that dFMRP is involved in processes from NB reactivation to the proper establishment and maintenance of the cytoskeleton to the regulation of inhibitory and excitatory circuits. Moreover, dFMRP was observed to play a role in RNA editing and trans-synaptic signaling in larval NMJs. From a behavioral and cognitive standpoint, recent studies of the Drosophila model of FXS allowed for the discovery of novel therapeutic targets and lead to the identification of specific cellular populations that contribute to the observed memory, circadian, and sleep deficits. dFMRP was also found to be involved in the DNA damage response and the response to cellular stressors. The potential link between FMRP and cancer susceptibility is particularly intriguing at a translational level. Viewing the current literature through a broader lens is useful both for re-evaluation of existing data as well as for exploring the non-neuronal, systemic aspects of FXS. Future experiments in the dfmr1 null flies would be particularly advantageous because the vast array of genetic manipulations available in Drosophila allow for expedient determination of the precise spatial and temporal requirements for dFMRP. These experiments would enable researchers to ascertain critical time points for interventions as well as explore the influence of variability in genetic background on treatment efficacy with a much greater degree of statistical power than can be achieved in clinical studies.

Ultimately, it is an exciting time in FXS research because the field is at an ideological crossroads. The etiology of FXS and the hallmark symptoms observed in human patients are well characterized, however, there is still much to be learned with regard to the molecular underpinnings of FXS. This incomplete understanding of the precise mechanisms that contribute to disease pathogenesis has 
precluded the identification of effective therapeutic approaches to improve the lives of affected individuals. The most salient example of this problem is the recent finding from two independent clinical trials that pharmacological treatment with mGluR antagonists failed to provide therapeutic benefit to FXS patients. Moving forward, there are several ways in which more stringent preclinical research can improve the likelihood of future success. One important contribution would be the identification of biomarkers that clinicians could use to assess which patients would be the best candidates for treatment with certain therapeutic approaches. The discovery of biomarkers would also provide objective, quantitative measures of treatment efficacy, as clinical trials are currently limited to subjective assessments. Additionally, once a therapeutic target has been identified, there should be preclinical efforts to determine whether there are any interactions between the therapeutic candidate and the combination of medications prescribed to FXS patients. It is possible that the clinical trials with mGluR antagonists were unable to detect a therapeutic effect because other medications in the patients' treatment regimen modulated or impaired the activity of the mGluR antagonists used in the studies. This can be easily addressed at the preclinical stage in Drosophila or mice by administering a combination of the medications currently used to treat FXS patients along with a promising therapeutic target such as mGluR inhibitors in several different genetic backgrounds to determine whether this intervention is able to ameliorate the observed defects in a context that more closely reflects the patient population. Given the widespread phenotypes and medical problems found to be associated with FXS, it may not be realistic to expect a panacea. However, the identification of relevant biomarkers along with discovery of more ubiquitous therapeutic targets that reduce the number of medications necessary to improve the lives of affected individuals constitute profound and achievable goals for the field.

Acknowledgments:

T.A.J. was supported by DOD grant number DOD-Autism Grant AR1101189 and E.D.W. was supported by the McMorris Autism Program. 
Impaired immediate recall and short-term memory in courtship conditioning paradigm (McBride et al., 2005)

Cognitive Impairment Impaired long-term memory in courtship conditioning paradigm (Banerjee et al., 2010) Impaired immediate recall and long-term memory in olfactory conditioning assay (Bolduc et al., 2008)
Impaired spatial learning (Guo et al., 2012; Yan et al., 2004)

Impaired passive avoidance (Ding et al., 2014;

Michalon et al., 2012; Yuskaitis et al., 2010)

Deficits in cued and contextual fear conditioning

(Ding et al., 2014; Guo et al., 2012; Olmos-

Serrano et al., 2011)

Reversal learning deficit (Bakker et al., 1994;

Perchiacca et al., 2012)

Impaired novel object recognition (King and Jope, 2013; Perchiacca et al., 2012)

Arrhythmic circadian activity and defective clock output (Dockendorff et al., 2002; Inoue et al., 2002; Morales et al., 2002)

Increased sleep that is more resistant to arousal (Bushey et al., 2009)

Length of circadian period shortened (Zhang et al., 2008)
Increased aversion to mirror (Spencer et al., 2005)

Failure to distinguish novel social stimulus (Mines et al., 2010; Perchiacca et al., 2012; Pietropaolo et al., 2011)

Failure of males to maintain interest in courtship (Dockendorff et al., 2002)

Abnormal social and repetitive behavior

Reduced social interaction (Bolduc et al., 2010b) Excessive grooming (Tauber et al., 2011)
Males interact less with novel females

(Pietropaolo et al., 2011)

Altered ultrasonic vocalizations in pups and adults (Lai et al., 2014; Rotschafer et al., 2012) Increased self-grooming (McNaughton et al., 2008; Pietropaolo et al., 2011)

Increased marble burying (Spencer et al., 2011;

Veeraragavan et al., 2011)
Intellectual disability (Hall et al., 2008,

Skinner et al., 2005)

Working memory impairment (Baker et al., 2011; Cornish et al., 2001)

Difficulty with falling asleep and sleep maintenance (Gould et al., 2000; Kronk et al., 2010; Kronk et al., 2009)

Snoring and obstructive sleep apnea (Kronk et al., 2009)
High incidence of social anxiety (Cordeiro et al., 2011; Hall et al., 2009) Delayed language development (Finestack and Abbeduto, 2010; Roberts et al., 2001) Repetitive and self-injurious behavior (Symons et al., 2003; Wolff et al., 2013)
Synaptic overgrowth at neuromuscular junction (Zhang et al., 2001)

Lateral neurons show abnormal branching

Neuronal Architecture Defects
(Dockendorff et al., 2002; Morales et al., 2002)

Branching and axon guidance defects in dorsal neurons (Morales et al., 2002)

Cross-over of mushroom body $\beta$-lobes (Michel et al., 2004; Reeve et al., 2005)
Increased dendritic spine density and length (Comery et al., 1997; Irwin et al., 2002; Nimchinsky et al., 2001)
Increased spine density with elongated spines (Hinton et al., 1991; Irwin et al., 2001; Wisniewski et al., 1991)

Table 1. Comparison of phenotypes in Drosophila and mouse models of fragile X with symptoms seen in human patients. 


\section{References:}

Adusei, D.C., Pacey, L.K., Chen, D., Hampson, D.R., 2010. Early developmental alterations in GABAergic protein expression in fragile $X$ knockout mice. Neuropharmacology 59, 167-171. [doi:10.1016/j.neuropharm.2010.05.002]

Alpatov, R., Lesch, B.J., Nakamoto-Kinoshita, M., Blanco, A., Chen, S., Stutzer, A., Armache, K.J., Simon, M.D., Xu, C., Ali, M., Murn, J., Prisic, S., Kutateladze, T.G., Vakoc, C.R., Min, J., Kingston, R.E., Fischle, W., Warren, S.T., Page, D.C., Shi, Y., 2014. A chromatin-dependent role of the fragile $\mathrm{X}$ mental retardation protein FMRP in the DNA damage response. Cell 157, 869-881. [doi:10.1016/j.cell.2014.03.040]

Ashley, C.T., Jr., Wilkinson, K.D., Reines, D., Warren, S.T., 1993. FMR1 protein: conserved RNP family domains and selective RNA binding. Science 262, 563-566. [doi:10.1126/science.7692601 ]

Baker, S., Hooper, S., Skinner, M., Hatton, D., Schaaf, J., Ornstein, P., Bailey, D., 2011. Working memory subsystems and task complexity in young boys with Fragile $\mathrm{X}$ syndrome. Journal of intellectual disability research : JIDR 55, 19-29. [doi:10.1111/j.1365-2788.2010.01343.x]

Bakker, C.E., C., V., Willemsen, R., van der Helm, R., Oerlemans, F., M., V., Bygrave, A., A.T., H., E., R., De Boulle, K., D'Hooge, R., Cras, P., van Velzen, D., Nagels, G., Martin, J., De Deyn, P.P., Darby, J.K., Oostra, B.A., Willems, P.J., 1994. Fmr1 knockout mice: a model to study fragile X mental retardation. . Cell 78, 23-33. [doi:10.1016/0092-8674(94)90569-X]

Banerjee, P., Schoenfeld, B.P., Bell, A.J., Choi, C.H., Bradley, M.P., Hinchey, P., Kollaros, M., Park, J.H., McBride, S.M., Dockendorff, T.C., 2010. Short- and long-term memory are modulated by multiple isoforms of the fragile $X$ mental retardation protein. The Journal of neuroscience : the official journal of the Society for Neuroscience 30, 6782-6792. [doi:10.1523/JNEUROSCI.6369-09.2010]

Bassell, G.J., 2011. Fragile balance: RNA editing tunes the synapse. Nature neuroscience 14, 1492-1494. [doi:10.1038/nn.2982]

Bear, M.F., Huber, K.M., Warren, S.T., 2004. The mGluR theory of fragile X mental retardation. Trends in neurosciences 27, 370-377. [doi:10.1016/j.tins.2004.04.009]

Bechara, E.G., Didiot, M.C., Melko, M., Davidovic, L., Bensaid, M., Martin, P., Castets, M., Pognonec, P., Khandjian, E.W., Moine, H., Bardoni, B., 2009. A novel function for fragile $X$ mental retardation protein in translational activation. PLoS biology 7, e16. [doi:10.1371/journal.pbio.1000016]

Bhogal, B., Jepson, J.E., Savva, Y.A., Pepper, A.S., Reenan, R.A., Jongens, T.A., 2011. Modulation of dADAR-dependent RNA editing by the Drosophila fragile $X$ mental retardation protein. Nature neuroscience 14, 1517-1524. [doi:10.1038/nn.2950]

Bilousova, T.V., Dansie, L., Ngo, M., Aye, J., Charles, J.R., Ethell, D.W., Ethell, I.M., 2009. Minocycline promotes dendritic spine maturation and improves behavioural performance in the fragile $X$ mouse model. Journal of medical genetics 46, 94-102. [doi:10.1136/jmg.2008.061796]

Bolduc, F.V., Bell, K., Cox, H., Broadie, K.S., Tully, T., 2008. Excess protein synthesis in Drosophila fragile X mutants impairs long-term memory. Nature neuroscience 11, 1143-1145. [doi:10.1038/nn.2175] 
Bolduc, F.V., Bell, K., Rosenfelt, C., Cox, H., Tully, T., 2010a. Fragile x mental retardation 1 and filamin a interact genetically in Drosophila long-term memory. Frontiers in neural circuits 3, 22. [doi:10.3389/neuro.04.022.2009]

Bolduc, F.V., Valente, D., Nguyen, A.T., Mitra, P.P., Tully, T., 2010b. An assay for social interaction in Drosophila Fragile X mutants. Fly 4, 216-225. [doi:10.4161/fly.4.3.12280]

Brown, V., Jin, P., Ceman, S., Darnell, J.C., O'Donnell, W.T., Tenenbaum, S.A., Jin, X., Feng, Y., Wilkinson, K.D., Keene, J.D., Darnell, R.B., Warren, S.T., 2001. Microarray identification of FMRP-associated brain mRNAs and altered mRNA translational profiles in fragile $X$ syndrome. Cell 107, 477-487. [doi:10.1016/S0092-8674(01)00568-2]

Brown, V., Small, K., Lakkis, L., Feng, Y., Gunter, C., Wilkinson, K.D., Warren, S.T., 1998. Purified recombinant Fmrp exhibits selective RNA binding as an intrinsic property of the fragile $\mathrm{X}$ mental retardation protein. The Journal of biological chemistry 273, 15521-15527. [doi:10.1074/jbc.273.25.15521]

Bushey, D., Tononi, G., Cirelli, C., 2009. The Drosophila fragile X mental retardation gene regulates sleep need. The Journal of neuroscience : the official journal of the Society for Neuroscience 29, 1948-1961. [doi:10.1523/JNEUROSCI.4830-08.2009]

Bushey, D., Tononi, G., Cirelli, C., 2011. Sleep and synaptic homeostasis: structural evidence in Drosophila. Science 332, 1576-1581. [doi:10.1126/science.1202839]

Callan, M.A., Cabernard, C., Heck, J., Luois, S., Doe, C.Q., Zarnescu, D.C., 2010. Fragile X protein controls neural stem cell proliferation in the Drosophila brain. Human molecular genetics 19, 3068-3079. [doi:10.1093/hmg/ddq213]

Callan, M.A., Clements, N., Ahrendt, N., Zarnescu, D.C., 2012. Fragile X Protein is required for inhibition of insulin signaling and regulates glial-dependent neuroblast reactivation in the developing brain. Brain research 1462, 151-161. [doi:10.1016/j.brainres.2012.03.042]

Callan, M.A., Zarnescu, D.C., 2011. Heads-up: new roles for the fragile $X$ mental retardation protein in neural stem and progenitor cells. Genesis 49, 424-440. [doi:10.1002/dvg.20745]

Castets, M., Schaeffer, C., Bechara, E., Schenck, A., Khandjian, E.W., Luche, S., Moine, H., Rabilloud, T., Mandel, J.L., Bardoni, B., 2005. FMRP interferes with the Rac1 pathway and controls actin cytoskeleton dynamics in murine fibroblasts. Human molecular genetics 14, 835-844. [doi:10.1093/hmg/ddi077]

Caudy, A.A., Myers, M., Hannon, G.J., Hammond, S.M., 2002. Fragile X-related protein and VIG associate with the RNA interference machinery. Genes \& development 16, 2491-2496. [doi:10.1101/gad.1025202]

Cea-Del Rio, C.A., Huntsman, M.M., 2014. The contribution of inhibitory interneurons to circuit dysfunction in Fragile $X$ Syndrome. Frontiers in cellular neuroscience 8, 245. [doi:10.3389/fncel.2014.00245] 
Chang, S., Bray, S.M., Li, Z., Zarnescu, D.C., He, C., Jin, P., Warren, S.T., 2008. Identification of small molecules rescuing fragile $X$ syndrome phenotypes in Drosophila. Nature chemical biology 4, 256-263. [doi:10.1038/nchembio.78]

Chell, J.M., Brand, A.H., 2010. Nutrition-responsive glia control exit of neural stem cells from quiescence. Cell 143, 1161-1173. [doi:10.1016/j.cell.2010.12.007]

Chen, L., Yun, S.W., Seto, J., Liu, W., Toth, M., 2003. The fragile X mental retardation protein binds and regulates a novel class of mRNAs containing $U$ rich target sequences. Neuroscience 120, 1005-1017. [doi:10.1016/S0306-4522(03)00406-8]

Chen, L.Y., Rex, C.S., Babayan, A.H., Kramar, E.A., Lynch, G., Gall, C.M., Lauterborn, J.C., 2010. Physiological activation of synaptic Rac $>$ PAK ( $p-21$ activated kinase) signaling is defective in a mouse model of fragile $X$ syndrome. The Journal of neuroscience : the official journal of the Society for Neuroscience 30, 10977-10984. [doi:10.1523/JNEUROSCI.1077-10.2010]

Choi, C.H., McBride, S.M., Schoenfeld, B.P., Liebelt, D.A., Ferreiro, D., Ferrick, N.J., Hinchey, P., Kollaros, M., Rudominer, R.L., Terlizzi, A.M., Koenigsberg, E., Wang, Y., Sumida, A., Nguyen, H.T., Bell, A.J., McDonald, T.V., Jongens, T.A., 2010. Age-dependent cognitive impairment in a Drosophila fragile $X$ model and its pharmacological rescue. Biogerontology 11, 347-362. [doi:10.1007/s10522-009-9259-6]

Choi, C.H., Schoenfeld, B.P., Weisz, E.D., Bell, A.J., Chambers, D.B., Hinchey, J., Choi, R.J., Hinchey, P., Kollaros, M., Gertner, M.J., Ferrick, N.J., Terlizzi, A.M., Yohn, N., Koenigsberg, E., Liebelt, D.A., Zukin, R.S., Woo, N.H., Tranfaglia, M.R., Louneva, N., Arnold, S.E., Siegel, S.J., Bolduc, F.V., McDonald, T.V., Jongens, T.A., McBride, S.M., 2015. PDE-4 Inhibition Rescues Aberrant Synaptic Plasticity in Drosophila and Mouse Models of Fragile X Syndrome. The Journal of neuroscience : the official journal of the Society for Neuroscience 35, 396-408. [doi:10.1523/JNEUROSCI.1356-12.2015]

Comery, T.A., Harris, J.B., Willems, P.J., Oostra, B.A., Irwin, S.A., Weiler, I.J., Greenough, W.T., 1997. Abnormal dendritic spines in fragile $X$ knockout mice: maturation and pruning deficits. Proceedings of the National Academy of Sciences of the United States of America 94, 5401-5404. [doi:10.1073/pnas.94.10.5401]

Cordeiro, L., Ballinger, E., Hagerman, R., Hessl, D., 2011. Clinical assessment of DSM-IV anxiety disorders in fragile $X$ syndrome: prevalence and characterization. Journal of neurodevelopmental disorders $3,57-$ 67. [doi:10.1007/s11689-010-9067-y]

Cornish, K.M., Munir, F., Cross, G., 2001. Differential impact of the FMR-1 full mutation on memory and attention functioning : a neuropsychological perspective. Journal of cognitive neuroscience 13, 144-150. [doi:10.1162/089892901564126]

D'Hulst, C., Heulens, I., Brouwer, J.R., Willemsen, R., De Geest, N., Reeve, S.P., De Deyn, P.P., Hassan, B.A., Kooy, R.F., 2009. Expression of the GABAergic system in animal models for fragile $X$ syndrome and fragile $X$ associated tremor/ataxia syndrome (FXTAS). Brain research 1253, 176-183. [doi:10.1016/j.brainres.2008.11.075] 
Darnell, J.C., Fraser, C.E., Mostovetsky, O., Darnell, R.B., 2009. Discrimination of common and unique RNA-binding activities among Fragile $X$ mental retardation protein paralogs. Human molecular genetics 18, 3164-3177. [doi:10.1093/hmg/ddp255]

Darnell, J.C., Klann, E., 2013. The translation of translational control by FMRP: therapeutic targets for FXS. Nature neuroscience 16, 1530-1536. [doi:10.1038/nn.3379]

Darnell, J.C., Mostovetsky, O., Darnell, R.B., 2005. FMRP RNA targets: identification and validation. Genes, brain, and behavior 4, 341-349. [doi:10.1111/j.1601-183X.2005.00144.x]

Darnell, J.C., Van Driesche, S.J., Zhang, C., Hung, K.Y., Mele, A., Fraser, C.E., Stone, E.F., Chen, C., Fak, J.J., Chi, S.W., Licatalosi, D.D., Richter, J.D., Darnell, R.B., 2011. FMRP stalls ribosomal translocation on mRNAs linked to synaptic function and autism. Cell 146, 247-261. [doi:10.1016/j.cell.2011.06.013]

Dictenberg, J.B., Swanger, S.A., Antar, L.N., Singer, R.H., Bassell, G.J., 2008. A direct role for FMRP in activity-dependent dendritic mRNA transport links filopodial-spine morphogenesis to fragile $X$ syndrome. Developmental cell 14, 926-939. [doi:10.1016/j.devcel.2008.04.003]

Ding, Q., Sethna, F., Wang, H., 2014. Behavioral analysis of male and female Fmr1 knockout mice on C57BL/6 background. Behavioural brain research 271, 72-78. [doi:10.1016/j.bbr.2014.05.046]

Dockendorff, T.C., Su, H.S., McBride, S.M., Yang, Z., Choi, C.H., Siwicki, K.K., Sehgal, A., Jongens, T.A., 2002. Drosophila lacking dfmr1 activity show defects in circadian output and fail to maintain courtship interest. Neuron 34, 973-984. [doi:10.1016/S0896-6273(02)00724-9]

Dolan, B.M., Duron, S.G., Campbell, D.A., Vollrath, B., Shankaranarayana Rao, B.S., Ko, H.Y., Lin, G.G., Govindarajan, A., Choi, S.Y., Tonegawa, S., 2013. Rescue of fragile X syndrome phenotypes in Fmr1 KO mice by the small-molecule PAK inhibitor FRAX486. Proceedings of the National Academy of Sciences of the United States of America 110, 5671-5676. [doi:10.1073/pnas.1219383110]

Dolen, G., Osterweil, E., Rao, B.S., Smith, G.B., Auerbach, B.D., Chattarji, S., Bear, M.F., 2007. Correction of fragile $X$ syndrome in mice. Neuron 56, 955-962. [doi:10.1016/j.neuron.2007.12.001]

Doll, C.A., Broadie, K., 2014. Impaired activity-dependent neural circuit assembly and refinement in autism spectrum disorder genetic models. Frontiers in cellular neuroscience 8, 30. [doi:10.3389/fncel.2014.00030]

El Idrissi, A., Ding, X.H., Scalia, J., Trenkner, E., Brown, W.T., Dobkin, C., 2005. Decreased GABA(A) receptor expression in the seizure-prone fragile $X$ mouse. Neuroscience letters 377, 141-146. [doi:10.1016/j.neulet.2004.11.087]

Estes, P.S., O'Shea, M., Clasen, S., Zarnescu, D.C., 2008. Fragile X protein controls the efficacy of mRNA transport in Drosophila neurons. Molecular and cellular neurosciences 39, 170-179. [doi:10.1016/j.mcn.2008.06.012]

Finestack, L.H., Abbeduto, L., 2010. Expressive language profiles of verbally expressive adolescents and young adults with Down syndrome or fragile $X$ syndrome. Journal of speech, language, and hearing research : JSLHR 53, 1334-1348. [doi:10.1044/1092-4388(2010/09-0125)] 
Franklin, A.V., King, M.K., Palomo, V., Martinez, A., McMahon, L.L., Jope, R.S., 2014. Glycogen synthase kinase- 3 inhibitors reverse deficits in long-term potentiation and cognition in fragile $\mathrm{X}$ mice. Biological psychiatry 75, 198-206. [doi:10.1016/j.biopsych.2013.08.003]

Friedman, S.H., Dani, N., Rushton, E., Broadie, K., 2013. Fragile X mental retardation protein regulates trans-synaptic signaling in Drosophila. Disease models \& mechanisms 6, 1400-1413. [doi:10.1242/dmm.012229]

Fu, Y.H., Kuhl, D.P., Pizzuti, A., Pieretti, M., Sutcliffe, J.S., Richards, S., Verkerk, A.J., Holden, J.J., Fenwick, R.G., Jr., Warren, S.T., et al., 1991. Variation of the CGG repeat at the fragile $X$ site results in genetic instability: resolution of the Sherman paradox. Cell 67, 1047-1058. [doi:10.1016/0092-8674(91)902835]

Gareau, C., Houssin, E., Martel, D., Coudert, L., Mellaoui, S., Huot, M.E., Laprise, P., Mazroui, R., 2013. Characterization of fragile $\mathrm{X}$ mental retardation protein recruitment and dynamics in Drosophila stress granules. PloS one 8, e55342. [doi:10.1371/journal.pone.0055342]

Gatto, C.L., Broadie, K., 2008. Temporal requirements of the fragile $X$ mental retardation protein in the regulation of synaptic structure. Development 135, 2637-2648. [doi:10.1242/dev.022244]

Gatto, C.L., Broadie, K., 2009. The fragile $X$ mental retardation protein in circadian rhythmicity and memory consolidation. Molecular neurobiology 39, 107-129. [doi:10.1007/s12035-009-8057-0]

Gatto, C.L., Broadie, K., 2010. Genetic controls balancing excitatory and inhibitory synaptogenesis in neurodevelopmental disorder models. Frontiers in synaptic neuroscience 2, 4. [doi:10.3389/fnsyn.2010.00004]

Gatto, C.L., Broadie, K., 2011. Fragile X mental retardation protein is required for programmed cell death and clearance of developmentally-transient peptidergic neurons. Developmental biology 356, 291-307. [doi:10.1016/j.ydbio.2011.05.001]

Gatto, C.L., Pereira, D., Broadie, K., 2014. GABAergic circuit dysfunction in the Drosophila Fragile X syndrome model. Neurobiology of disease 65, 142-159. [doi:10.1016/j.nbd.2014.01.008]

Gould, E.L., Loesch, D.Z., Martin, M.J., Hagerman, R.J., Armstrong, S.M., Huggins, R.M., 2000. Melatonin profiles and sleep characteristics in boys with fragile $X$ syndrome: a preliminary study. American journal of medical genetics 95, 307-315. [doi:10.1002/1096-8628(20001211)]

Greenspan, R.J., Ferveur, J.F., 2000. Courtship in Drosophila. Annual review of genetics 34, 205-232. [doi:10.1146/annurev.genet.34.1.205]

Guo, W., Allan, A.M., Zong, R., Zhang, L., Johnson, E.B., Schaller, E.G., Murthy, A.C., Goggin, S.L., Eisch, A.J., Oostra, B.A., Nelson, D.L., Jin, P., Zhao, X., 2011. Ablation of Fmrp in adult neural stem cells disrupts hippocampus-dependent learning. Nature medicine 17, 559-565. [doi:10.1038/nm.2336] 
Guo, W., Murthy, A.C., Zhang, L., Johnson, E.B., Schaller, E.G., Allan, A.M., Zhao, X., 2012. Inhibition of GSK3beta improves hippocampus-dependent learning and rescues neurogenesis in a mouse model of fragile $X$ syndrome. Human molecular genetics 21, 681-691. [doi:10.1093/hmg/ddr501]

Hall, S.S., Burns, D.D., Lightbody, A.A., Reiss, A.L., 2008. Longitudinal changes in intellectual development in children with Fragile $X$ syndrome. Journal of abnormal child psychology 36, 927-939. [doi:10.1007/s10802-008-9223-y]

Hall, S.S., Lightbody, A.A., Huffman, L.C., Lazzeroni, L.C., Reiss, A.L., 2009. Physiological correlates of social avoidance behavior in children and adolescents with fragile $\mathrm{x}$ syndrome. Journal of the American Academy of Child and Adolescent Psychiatry 48, 320-329. [doi:10.1097/CHI.0b013e318195bd15]

Hayashi, M.L., Rao, B.S., Seo, J.S., Choi, H.S., Dolan, B.M., Choi, S.Y., Chattarji, S., Tonegawa, S., 2007. Inhibition of p21-activated kinase rescues symptoms of fragile $X$ syndrome in mice. Proceedings of the National Academy of Sciences of the United States of America 104, 11489-11494. [doi:10.1073/pnas.0705003104]

Henderson, C., Wijetunge, L., Kinoshita, M.N., Shumway, M., Hammond, R.S., Postma, F.R., Brynczka, C., Rush, R., Thomas, A., Paylor, R., Warren, S.T., Vanderklish, P.W., Kind, P.C., Carpenter, R.L., Bear, M.F., Healy, A.M., 2012. Reversal of disease-related pathologies in the fragile $X$ mouse model by selective activation of GABAB receptors with arbaclofen. Science translational medicine 4, 152ra128. [doi:10.1126/scitranslmed.3004218]

Heulens, I., D'Hulst, C., Van Dam, D., De Deyn, P.P., Kooy, R.F., 2012. Pharmacological treatment of fragile $X$ syndrome with GABAergic drugs in a knockout mouse model. Behavioural brain research 229, 244-249. [doi:10.1016/j.bbr.2012.01.031]

Hinton, V.J., Brown, W.T., Wisniewski, K., Rudelli, R.D., 1991. Analysis of neocortex in three males with the fragile $X$ syndrome. American journal of medical genetics 41, 289-294. [doi:10.1002/ajmg.1320410306]

Inoue, S., Shimoda, M., Nishinokubi, I., Siomi, M.C., Okamura, M., Nakamura, A., Kobayashi, S., Ishida, N., Siomi, H., 2002. A role for the Drosophila fragile X-related gene in circadian output. Current biology : CB 12, 1331-1335. [doi:10.1016/S0960-9822(02)01036-9]

Irwin, S.A., Idupulapati, M., Gilbert, M.E., Harris, J.B., Chakravarti, A.B., Rogers, E.J., Crisostomo, R.A., Larsen, B.P., Mehta, A., Alcantara, C.J., Patel, B., Swain, R.A., Weiler, I.J., Oostra, B.A., Greenough, W.T., 2002. Dendritic spine and dendritic field characteristics of layer $V$ pyramidal neurons in the visual cortex of fragile-X knockout mice. American journal of medical genetics 111, 140-146. [doi:10.1002/ajmg.10500]

Irwin, S.A., Patel, B., Idupulapati, M., Harris, J.B., Crisostomo, R.A., Larsen, B.P., Kooy, F., Willems, P.J., Cras, P., Kozlowski, P.B., Swain, R.A., Weiler, I.J., Greenough, W.T., 2001. Abnormal dendritic spine characteristics in the temporal and visual cortices of patients with fragile-X syndrome: a quantitative examination. American journal of medical genetics 98, 161-167. [doi:10.1002/10968628(20010115)98:2\%3C161::AID-AJMG1025\%3E3.0.CO;2-B] 
Ishizuka, A., Siomi, M.C., Siomi, H., 2002. A Drosophila fragile X protein interacts with components of RNAi and ribosomal proteins. Genes \& development 16, 2497-2508. [doi:10.1101/gad.1022002]

Janusz, A., Milek, J., Perycz, M., Pacini, L., Bagni, C., Kaczmarek, L., Dziembowska, M., 2013. The Fragile X mental retardation protein regulates matrix metalloproteinase 9 mRNA at synapses. The Journal of neuroscience : the official journal of the Society for Neuroscience 33, 18234-18241. [doi:10.1523/JNEUROSCI.2207-13.2013]

Jin, P., Zarnescu, D.C., Ceman, S., Nakamoto, M., Mowrey, J., Jongens, T.A., Nelson, D.L., Moses, K., Warren, S.T., 2004. Biochemical and genetic interaction between the fragile $X$ mental retardation protein and the microRNA pathway. Nature neuroscience 7, 113-117. [doi:10.1038/nn1174]

Kanellopoulos, A.K., Semelidou, O., Kotini, A.G., Anezaki, M., Skoulakis, E.M., 2012. Learning and memory deficits consequent to reduction of the fragile $X$ mental retardation protein result from metabotropic glutamate receptor-mediated inhibition of cAMP signaling in Drosophila. The Journal of neuroscience : the official journal of the Society for Neuroscience 32, 13111-13124. [doi:10.1523/JNEUROSCI.1347-12.2012]

Kelley, D.J., Davidson, R.J., Elliott, J.L., Lahvis, G.P., Yin, J.C., Bhattacharyya, A., 2007. The cyclic AMP cascade is altered in the fragile $X$ nervous system. PloS one 2, e931. [doi:10.1371/journal.pone.0000931]

Kidd, S.A., Lachiewicz, A., Barbouth, D., Blitz, R.K., Delahunty, C., McBrien, D., Visootsak, J., Berry-Kravis, E., 2014. Fragile $X$ syndrome: a review of associated medical problems. Pediatrics 134, 995-1005. [doi:10.1542/peds.2013-4301]

Kim, S.H., Dong, W.K., Weiler, I.J., Greenough, W.T., 2006. Fragile X mental retardation protein shifts between polyribosomes and stress granules after neuronal injury by arsenite stress or in vivo hippocampal electrode insertion. The Journal of neuroscience : the official journal of the Society for Neuroscience 26, 2413-2418. [doi:10.1523/JNEUROSCI.3680-05.2006]

King, M.K., Jope, R.S., 2013. Lithium treatment alleviates impaired cognition in a mouse model of fragile $X$ syndrome. Genes, brain, and behavior 12, 723-731. [doi:10.1111/gbb.12071]

Kronk, R., Bishop, E.E., Raspa, M., Bickel, J.O., Mandel, D.A., Bailey, D.B., Jr., 2010. Prevalence, nature, and correlates of sleep problems among children with fragile $\mathrm{X}$ syndrome based on a large scale parent survey. Sleep 33, 679-687.

Kronk, R., Dahl, R., Noll, R., 2009. Caregiver reports of sleep problems on a convenience sample of children with fragile $X$ syndrome. American journal on intellectual and developmental disabilities 114, 383-392. [doi:10.1352/1944-7588-114.6.383]

Krueger, D.D., Osterweil, E.K., Chen, S.P., Tye, L.D., Bear, M.F., 2011. Cognitive dysfunction and prefrontal synaptic abnormalities in a mouse model of fragile $X$ syndrome. Proceedings of the National Academy of Sciences of the United States of America 108, 2587-2592. [doi:10.1073/pnas.1013855108]

Lai, J.K., Sobala-Drozdowski, M., Zhou, L., Doering, L.C., Faure, P.A., Foster, J.A., 2014. Temporal and spectral differences in the ultrasonic vocalizations of fragile $X$ knock out mice during postnatal development. Behavioural brain research 259, 119-130. [doi:10.1016/j.bbr.2013.10.049] 
Lee, A., Li, W., Xu, K., Bogert, B.A., Su, K., Gao, F.B., 2003. Control of dendritic development by the Drosophila fragile X-related gene involves the small GTPase Rac1. Development 130, 5543-5552. [doi:10.1242/dev.00792]

Leigh, M.J., Nguyen, D.V., Mu, Y., Winarni, T.I., Schneider, A., Chechi, T., Polussa, J., Doucet, P., Tassone, F., Rivera, S.M., Hessl, D., Hagerman, R.J., 2013. A randomized double-blind, placebo-controlled trial of minocycline in children and adolescents with fragile $x$ syndrome. Journal of developmental and behavioral pediatrics : JDBP 34, 147-155. [doi:10.1097/DBP.0b013e318287cd17]

Linder, B., Plottner, O., Kroiss, M., Hartmann, E., Laggerbauer, B., Meister, G., Keidel, E., Fischer, U., 2008. Tdrd3 is a novel stress granule-associated protein interacting with the Fragile-X syndrome protein FMRP. Human molecular genetics 17, 3236-3246. [doi:10.1093/hmg/ddn219]

Ling, S.C., Fahrner, P.S., Greenough, W.T., Gelfand, V.I., 2004. Transport of Drosophila fragile X mental retardation protein-containing ribonucleoprotein granules by kinesin-1 and cytoplasmic dynein. Proceedings of the National Academy of Sciences of the United States of America 101, 17428-17433. [doi:10.1073/pnas.0408114101]

Liu, W., Jiang, F., Bi, X., Zhang, Y.Q., 2012. Drosophila FMRP participates in the DNA damage response by regulating G2/M cell cycle checkpoint and apoptosis. Human molecular genetics 21, 4655-4668. [doi:10.1093/hmg/dds307]

Lozano, R., Hare, E.B., Hagerman, R.J., 2014. Modulation of the GABAergic pathway for the treatment of fragile X syndrome. Neuropsychiatric disease and treatment 10, 1769-1779. [doi:10.2147/NDT.S42919]

Lu, R., Wang, H., Liang, Z., Ku, L., O'Donnell W, T., Li, W., Warren, S.T., Feng, Y., 2004. The fragile X protein controls microtubule-associated protein $1 \mathrm{~B}$ translation and microtubule stability in brain neuron development. Proceedings of the National Academy of Sciences of the United States of America 101, 15201-15206. [doi:10.1073/pnas.0404995101]

Luca, R., Averna, M., Zalfa, F., Vecchi, M., Bianchi, F., La Fata, G., Del Nonno, F., Nardacci, R., Bianchi, M., Nuciforo, P., Munck, S., Parrella, P., Moura, R., Signori, E., Alston, R., Kuchnio, A., Farace, M.G., Fazio, V.M., Piacentini, M., De Strooper, B., Achsel, T., Neri, G., Neven, P., Evans, D.G., Carmeliet, P., Mazzone, M., Bagni, C., 2013. The fragile $X$ protein binds mRNAs involved in cancer progression and modulates metastasis formation. EMBO molecular medicine 5, 1523-1536. [doi:10.1002/emmm.201302847]

Luo, Y., Shan, G., Guo, W., Smrt, R.D., Johnson, E.B., Li, X., Pfeiffer, R.L., Szulwach, K.E., Duan, R., Barkho, B.Z., Li, W., Liu, C., Jin, P., Zhao, X., 2010. Fragile $x$ mental retardation protein regulates proliferation and differentiation of adult neural stem/progenitor cells. PLoS genetics 6, e1000898. [doi:10.1371/journal.pgen.1000898]

Mazroui, R., Huot, M.E., Tremblay, S., Filion, C., Labelle, Y., Khandjian, E.W., 2002. Trapping of messenger RNA by Fragile X Mental Retardation protein into cytoplasmic granules induces translation repression. Human molecular genetics 11, 3007-3017. [doi:10.1093/hmg/11.24.3007]

McBride, S.M., Choi, C.H., Wang, Y., Liebelt, D., Braunstein, E., Ferreiro, D., Sehgal, A., Siwicki, K.K., Dockendorff, T.C., Nguyen, H.T., McDonald, T.V., Jongens, T.A., 2005. Pharmacological rescue of synaptic 
plasticity, courtship behavior, and mushroom body defects in a Drosophila model of fragile $\mathrm{X}$ syndrome. Neuron 45, 753-764. [doi:10.1016/j.neuron.2005.01.038]

McNaughton, C.H., Moon, J., Strawderman, M.S., Maclean, K.N., Evans, J., Strupp, B.J., 2008. Evidence for social anxiety and impaired social cognition in a mouse model of fragile $X$ syndrome. Behavioral neuroscience 122, 293-300. [doi:10.1037/0735-7044.122.2.293]

Michalon, A., Sidorov, M., Ballard, T.M., Ozmen, L., Spooren, W., Wettstein, J.G., Jaeschke, G., Bear, M.F., Lindemann, L., 2012. Chronic pharmacological mGlu5 inhibition corrects fragile $X$ in adult mice. Neuron 74, 49-56. [doi:10.1016/j.neuron.2012.03.009]

Michel, C.I., Kraft, R., Restifo, L.L., 2004. Defective neuronal development in the mushroom bodies of Drosophila fragile $X$ mental retardation 1 mutants. The Journal of neuroscience : the official journal of the Society for Neuroscience 24, 5798-5809. [doi:10.1523/JNEUROSCI.1102-04.2004]

Mines, M.A., Yuskaitis, C.J., King, M.K., Beurel, E., Jope, R.S., 2010. GSK3 influences social preference and anxiety-related behaviors during social interaction in a mouse model of fragile $\mathrm{X}$ syndrome and autism. PloS one 5, e9706. [doi:10.1371/journal.pone.0009706]

Miyashiro, K.Y., Beckel-Mitchener, A., Purk, T.P., Becker, K.G., Barret, T., Liu, L., Carbonetto, S., Weiler, I.J., Greenough, W.T., Eberwine, J., 2003. RNA cargoes associating with FMRP reveal deficits in cellular functioning in Fmr1 null mice. Neuron 37, 417-431. [doi:10.1016/S0896-6273(03)00034-5]

Monzo, K., Papoulas, O., Cantin, G.T., Wang, Y., Yates, J.R., 3rd, Sisson, J.C., 2006. Fragile X mental retardation protein controls trailer hitch expression and cleavage furrow formation in Drosophila embryos. Proceedings of the National Academy of Sciences of the United States of America 103, 1816018165. [doi:10.1073/pnas.0606508103]

Morales, J., Hiesinger, P.R., Schroeder, A.J., Kume, K., Verstreken, P., Jackson, F.R., Nelson, D.L., Hassan, B.A., 2002. Drosophila fragile $X$ protein, DFXR, regulates neuronal morphology and function in the brain. Neuron 34, 961-972. [doi:10.1016/S0896-6273(02)00731-6]

Nimchinsky, E.A., Oberlander, A.M., Svoboda, K., 2001. Abnormal development of dendritic spines in FMR1 knock-out mice. The Journal of neuroscience : the official journal of the Society for Neuroscience 21, 5139-5146.

Olmos-Serrano, J.L., Corbin, J.G., Burns, M.P., 2011. The GABA(A) receptor agonist THIP ameliorates specific behavioral deficits in the mouse model of fragile $X$ syndrome. Developmental neuroscience 33, 395-403. [doi:10.1159/000332884]

Olmos-Serrano, J.L., Paluszkiewicz, S.M., Martin, B.S., Kaufmann, W.E., Corbin, J.G., Huntsman, M.M., 2010. Defective GABAergic neurotransmission and pharmacological rescue of neuronal hyperexcitability in the amygdala in a mouse model of fragile $X$ syndrome. The Journal of neuroscience : the official journal of the Society for Neuroscience 30, 9929-9938. [doi:10.1523/JNEUROSCI.1714-10.2010]

Paluszkiewicz, S.M., Martin, B.S., Huntsman, M.M., 2011. Fragile X syndrome: the GABAergic system and circuit dysfunction. Developmental neuroscience 33, 349-364. [doi:10.1159/000329420] 
Paribello, C., Tao, L., Folino, A., Berry-Kravis, E., Tranfaglia, M., Ethell, I.M., Ethell, D.W., 2010. Open-label add-on treatment trial of minocycline in fragile $X$ syndrome. BMC neurology 10, 91. [doi:10.1186/14712377-10-91]

Perchiacca, J.M., Ladiwala, A.R., Bhattacharya, M., Tessier, P.M., 2012. Structure-based design of conformation- and sequence-specific antibodies against amyloid beta. Proceedings of the National Academy of Sciences of the United States of America 109, 84-89. [doi:10.1073/pnas.1111232108]

Pieretti, M., Zhang, F.P., Fu, Y.H., Warren, S.T., Oostra, B.A., Caskey, C.T., Nelson, D.L., 1991. Absence of

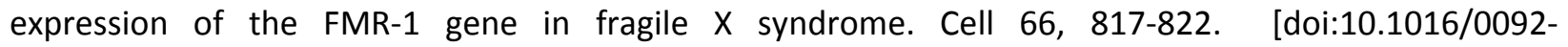
8674(91)90125-I]

Pietropaolo, S., Guilleminot, A., Martin, B., D'Amato, F.R., Crusio, W.E., 2011. Genetic-background modulation of core and variable autistic-like symptoms in Fmr1 knock-out mice. PloS one 6, e17073. [doi:10.1371/journal.pone.0017073]

Reeve, S.P., Bassetto, L., Genova, G.K., Kleyner, Y., Leyssen, M., Jackson, F.R., Hassan, B.A., 2005. The Drosophila fragile $X$ mental retardation protein controls actin dynamics by directly regulating profilin in the brain. Current biology : CB 15, 1156-1163. [doi:10.1016/j.cub.2005.05.050]

Renn, S.C., Park, J.H., Rosbash, M., Hall, J.C., Taghert, P.H., 1999. A pdf neuropeptide gene mutation and ablation of PDF neurons each cause severe abnormalities of behavioral circadian rhythms in Drosophila. Cell 99, 791-802. [doi:10.1016/S0092-8674(00)81676-1]

Roberts, J.E., Mirrett, P., Burchinal, M., 2001. Receptive and expressive communication development of young males with fragile $X$ syndrome. American journal of mental retardation : AJMR 106, 216-230. [doi:10.1352/0895-8017(2001)106<0216:RAECDO>2.0.CO;2]

Rotschafer, S.E., Trujillo, M.S., Dansie, L.E., Ethell, I.M., Razak, K.A., 2012. Minocycline treatment reverses ultrasonic vocalization production deficit in a mouse model of Fragile $X$ Syndrome. Brain research 1439, 7-14. [doi:10.1016/j.brainres.2011.12.041]

Saffary, R., Xie, Z., 2011. FMRP regulates the transition from radial glial cells to intermediate progenitor cells during neocortical development. The Journal of neuroscience : the official journal of the Society for Neuroscience 31, 1427-1439. [doi:10.1523/JNEUROSCI.4854-10.2011]

Santos, A.R., Kanellopoulos, A.K., Bagni, C., 2014. Learning and behavioral deficits associated with the absence of the fragile $X$ mental retardation protein: what a fly and mouse model can teach us. Learning \& memory 21, 543-555. [doi:10.1101/lm.035956.114]

Scharf, S.H., Jaeschke, G., Wettstein, J.G., Lindemann, L., 2014. Metabotropic glutamate receptor 5 as drug target for Fragile $X$ syndrome. Current opinion in pharmacology. [doi:10.1016/j.coph.2014.11.004]

Schreiner, A., Niehaus, D., Shuriquie, N.A., Aadamsoo, K., Korcsog, P., Salinas, R., Theodoropoulou, P., Fernandez, L.G., Ucok, A., Tessier, C., Bergmans, P., Hoeben, D., 2012. Metabolic effects of paliperidone extended release versus oral olanzapine in patients with schizophrenia: a prospective, randomized, controlled trial. Journal of clinical psychopharmacology 32, 449-457. [doi:10.1097/JCP.0b013e31825cccad] 
Schultz-Pedersen, S., Hasle, H., Olsen, J.H., Friedrich, U., 2001. Evidence of decreased risk of cancer in individuals with fragile X. American journal of medical genetics 103, 226-230. [doi:10.1002/ajmg.1533]

Sidhu, H., Dansie, L.E., Hickmott, P.W., Ethell, D.W., Ethell, I.M., 2014. Genetic removal of matrix metalloproteinase 9 rescues the symptoms of fragile $X$ syndrome in a mouse model. The Journal of neuroscience : the official journal of the Society for Neuroscience 34, 9867-9879. [doi:10.1523/JNEUROSCI.1162-14.2014]

Siegel, R.W., Hall, J.C., 1979. Conditioned responses in courtship behavior of normal and mutant Drosophila. Proceedings of the National Academy of Sciences of the United States of America 76, 34303434. [doi:10.1073/pnas.76.7.3430]

Siller, S.S., Broadie, K., 2011. Neural circuit architecture defects in a Drosophila model of Fragile $X$ syndrome are alleviated by minocycline treatment and genetic removal of matrix metalloproteinase. Disease models \& mechanisms 4, 673-685. [doi:10.1242/dmm.008045]

Siomi, H., Siomi, M.C., Nussbaum, R.L., Dreyfuss, G., 1993. The protein product of the fragile $X$ gene, FMR1, has characteristics of an RNA-binding protein. Cell 74, 291-298. [doi:10.1016/00928674(93)90420-U]

Skinner, M., Hooper, S., Hatton, D.D., Roberts, J., Mirrett, P., Schaaf, J., Sullivan, K., Wheeler, A., Bailey, D.B., Jr., 2005. Mapping nonverbal IQ in young boys with fragile $X$ syndrome. American journal of medical genetics. Part A 132A, 25-32. [doi:10.1002/ajmg.a.30353]

Sousa-Nunes, R., Yee, L.L., Gould, A.P., 2011. Fat cells reactivate quiescent neuroblasts via TOR and glial insulin relays in Drosophila. Nature 471, 508-512. [doi:10.1038/nature09867]

Spencer, C.M., Alekseyenko, O., Hamilton, S.M., Thomas, A.M., Serysheva, E., Yuva-Paylor, L.A., Paylor, R., 2011. Modifying behavioral phenotypes in Fmr1KO mice: genetic background differences reveal autistic-like responses. Autism research : official journal of the International Society for Autism Research 4, 40-56. [doi:10.1002/aur.168]

Spencer, C.M., Alekseyenko, O., Serysheva, E., Yuva-Paylor, L.A., Paylor, R., 2005. Altered anxiety-related and social behaviors in the Fmr1 knockout mouse model of fragile $X$ syndrome. Genes, brain, and behavior 4, 420-430. [doi:10.1111/j.1601-183X.2005.00123.x]

Sund, R., Pukkala, E., Patja, K., 2009. Cancer incidence among persons with fragile $X$ syndrome in Finland: a population-based study. Journal of intellectual disability research : JIDR 53, 85-90. [doi:10.1111/j.1365-2788.2008.01116.x]

Symons, F.J., Clark, R.D., Hatton, D.D., Skinner, M., Bailey, D.B., Jr., 2003. Self-injurious behavior in young boys with fragile $X$ syndrome. American journal of medical genetics. Part A 118A, 115-121. [doi:10.1002/ajmg.a.10078]

Tauber, J.M., Vanlandingham, P.A., Zhang, B., 2011. Elevated levels of the vesicular monoamine transporter and a novel repetitive behavior in the Drosophila model of fragile $\mathrm{X}$ syndrome. PloS one 6 , e27100. [doi:10.1371/journal.pone.0027100] 
Trotta, N., Orso, G., Rossetto, M.G., Daga, A., Broadie, K., 2004. The hereditary spastic paraplegia gene, spastin, regulates microtubule stability to modulate synaptic structure and function. Current biology : $C B$ 14, 1135-1147. [doi:10.1016/j.cub.2004.06.058]

Tully, T., Quinn, W.G., 1985. Classical conditioning and retention in normal and mutant Drosophila melanogaster. Journal of comparative physiology. A, Sensory, neural, and behavioral physiology 157, 263-277.

van Alphen, B., Yap, M.H., Kirszenblat, L., Kottler, B., van Swinderen, B., 2013. A dynamic deep sleep stage in Drosophila. The Journal of neuroscience : the official journal of the Society for Neuroscience 33, 6917-6927. [doi:10.1523/JNEUROSCI.0061-13.2013]

Veeraragavan, S., Bui, N., Perkins, J.R., Yuva-Paylor, L.A., Carpenter, R.L., Paylor, R., 2011. Modulation of behavioral phenotypes by a muscarinic $M 1$ antagonist in a mouse model of fragile $X$ syndrome. Psychopharmacology 217, 143-151. [doi:10.1007/s00213-011-2276-6]

Verkerk, A.J., Pieretti, M., Sutcliffe, J.S., Fu, Y.H., Kuhl, D.P., Pizzuti, A., Reiner, O., Richards, S., Victoria, M.F., Zhang, F.P., et al., 1991. Identification of a gene (FMR-1) containing a CGG repeat coincident with a breakpoint cluster region exhibiting length variation in fragile $X$ syndrome. Cell 65, 905-914. [doi:10.1016/0092-8674(91)90397-H]

Wan, L., Dockendorff, T.C., Jongens, T.A., Dreyfuss, G., 2000. Characterization of dFMR1, a Drosophila melanogaster homolog of the fragile $X$ mental retardation protein. Molecular and cellular biology 20, 8536-8547. [doi:10.1128/MCB.20.22.8536-8547.2000]

Wisniewski, K.E., Segan, S.M., Miezejeski, C.M., Sersen, E.A., Rudelli, R.D., 1991. The Fra(X) syndrome: neurological, electrophysiological, and neuropathological abnormalities. American journal of medical genetics 38, 476-480. [doi:10.1002/ajmg.1320380267]

Wolff, J.J., Hazlett, H.C., Lightbody, A.A., Reiss, A.L., Piven, J., 2013. Repetitive and self-injurious behaviors: associations with caudate volume in autism and fragile $X$ syndrome. Journal of neurodevelopmental disorders 5, 12. [doi:10.1186/1866-1955-5-12]

Xu, D., Shen, W., Guo, R., Xue, Y., Peng, W., Sima, J., Yang, J., Sharov, A., Srikantan, S., Yang, J., Fox, D., 3rd, Qian, Y., Martindale, J.L., Piao, Y., Machamer, J., Joshi, S.R., Mohanty, S., Shaw, A.C., Lloyd, T.E., Brown, G.W., Ko, M.S., Gorospe, M., Zou, S., Wang, W., 2013. Top3beta is an RNA topoisomerase that works with fragile $X$ syndrome protein to promote synapse formation. Nature neuroscience 16,1238 1247. [doi:10.1038/nn.3479]

Xu, K., Bogert, B.A., Li, W., Su, K., Lee, A., Gao, F.B., 2004. The fragile X-related gene affects the crawling behavior of Drosophila larvae by regulating the mRNA level of the DEG/ENaC protein pickpocket1. Current biology : CB 14, 1025-1034. [doi:10.1016/j.cub.2004.05.055]

Xu, S., Poidevin, M., Han, E., Bi, J., Jin, P., 2012. Circadian rhythm-dependent alterations of gene expression in Drosophila brain lacking fragile $X$ mental retardation protein. PloS one 7, e37937. [doi:10.1371/journal.pone.0037937] 
Yan, Q.J., Asafo-Adjei, P.K., Arnold, H.M., Brown, R.E., Bauchwitz, R.P., 2004. A phenotypic and molecular characterization of the fmr1-tm1Cgr fragile X mouse. Genes, brain, and behavior 3, 337-359. [doi:10.1111/j.1601-183X.2004.00087.x]

Yan, Q.J., Rammal, M., Tranfaglia, M., Bauchwitz, R.P., 2005. Suppression of two major Fragile X Syndrome mouse model phenotypes by the mGluR5 antagonist MPEP. Neuropharmacology 49, 10531066. [doi:10.1016/j.neuropharm.2005.06.004]

Yao, A., Jin, S., Li, X., Liu, Z., Ma, X., Tang, J., Zhang, Y.Q., 2011. Drosophila FMRP regulates microtubule network formation and axonal transport of mitochondria. Human molecular genetics 20, 51-63. [doi:10.1093/hmg/ddq431]

Yuskaitis, C.J., Mines, M.A., King, M.K., Sweatt, J.D., Miller, C.A., Jope, R.S., 2010. Lithium ameliorates altered glycogen synthase kinase- 3 and behavior in a mouse model of fragile $\mathrm{X}$ syndrome. Biochemical pharmacology 79, 632-646. [doi:10.1016/j.bcp.2009.09.023]

Zalfa, F., Eleuteri, B., Dickson, K.S., Mercaldo, V., De Rubeis, S., di Penta, A., Tabolacci, E., Chiurazzi, P., Neri, G., Grant, S.G., Bagni, C., 2007. A new function for the fragile $X$ mental retardation protein in regulation of PSD-95 mRNA stability. Nature neuroscience 10, 578-587. [doi:10.1038/nn1893]

Zhang, J., Fang, Z., Jud, C., Vansteensel, M.J., Kaasik, K., Lee, C.C., Albrecht, U., Tamanini, F., Meijer, J.H., Oostra, B.A., Nelson, D.L., 2008. Fragile X-related proteins regulate mammalian circadian behavioral rhythms. American journal of human genetics 83, 43-52. [doi:10.1016/j.ajhg.2008.06.003]

Zhang, W., Cheng, Y., Li, Y., Chen, Z., Jin, P., Chen, D., 2014. A feed-forward mechanism involving Drosophila fragile $X$ mental retardation protein triggers a replication stress-induced DNA damage response. Human molecular genetics 23, 5188-5196. [doi:10.1093/hmg/ddu241]

Zhang, Y.Q., Bailey, A.M., Matthies, H.J., Renden, R.B., Smith, M.A., Speese, S.D., Rubin, G.M., Broadie, K., 2001. Drosophila fragile X-related gene regulates the MAP1B homolog Futsch to control synaptic structure and function. Cell 107, 591-603. [doi:10.1016/S0092-8674(01)00589-X]

Zhang, Y.Q., Matthies, H.J., Mancuso, J., Andrews, H.K., Woodruff, E., 3rd, Friedman, D., Broadie, K., 2004. The Drosophila fragile $X$-related gene regulates axoneme differentiation during spermatogenesis. Developmental biology 270, 290-307. [doi:10.1016/j.ydbio.2004.02.010] 